\title{
Um, dois, três, quatro! Um estudo de caso de poliembrionia em Handroanthus serratifolius (Vahl) S. Grose, (Bignoniaceae), Maranhão, Brasil
}

\author{
One, two, three, four! A case study of polyembryony in Handroanthus \\ serratifolius (Vahl) S. Grose, (Bignoniaceae), Maranhão, Brazil
}

\author{
Ana Clara de Sousa Braga ${ }^{1}$, Guilherme Sousa da Silva ${ }^{2}$, Janilde de Melo Nascimento $\bullet 3$, \\ Gustavo da Silva Gomes ${ }^{4}$, Gonçalo Mendes da Conceição ${ }^{5 *}$
}

\begin{abstract}
${ }^{1}$ Bolsista de iniciação científica/PIBIC-UEMA/AGA, Universidade Estadual do Maranhão, Centro de Estudos Superiores de Caxias, Brasil. E-mail: anaclaraa19992017@gmail.com

2 Doutorando do Programa de Biologia Vegetal, Universidade Estadual de Campinas, Instituto de Biologia, Campinas-SP, Brasil. E-mail: guilhermecx.cx@hotmail.com

${ }^{3}$ Licenciada em Ciências Biológicas/UEMA e Mestre em Botânica Tropical/UFRA/MPEG. Brasil. E-mail: jad-nasci@hotmail.com

${ }^{4}$ Bolsista de iniciação científica/PIBIC-CNPq, Universidade Estadual do Maranhão, Centro de Estudos Superiores de Caxias, Brasil. E-mail: gustavocjk@gmail.com

${ }^{5}$ Professor Dr. do Centro de Estudos Superiores de Caxias/CESC, da Universidade Estadual do Maranhão/UEMA, Maranhão/Brasil; Programa de Pós-Graduação em Biodiversidade, Ambiente e Saúde/PPGBAS, Caxias/MA, Brasil. E-mail: doutorgoncalo@gmail.com *Autor para correspondência
\end{abstract}

\section{Palavras-chave \\ Germinação \\ Cerrado \\ Apomixia}

\begin{abstract}
O objetivo da pesquisa foi registrar e avaliar a frequência e efeitos da ocorrência de poliembrionia em Handroanthus serratifolius (Vahl) S. Grose, através de um estudo de caso observado na produção de mudas para o projeto de reflorestamento de áreas degradadas no Morro do Alecrim, Caxias-MA. Para obtenção das sementes foram coletados frutos maduros e secos de $H$. serratifolius, e realizados testes de germinação com as mesmas, evidenciando a existência de vários embriões em algumas sementes. Das 100 sementes submetidas ao teste observou-se a germinação de $70 \%$ das sementes, 47 apresentaram apenas um embrião e 16 desenvolveram poliembrionia onde 12 sementes germinaram duas plântulas, 3 sementes emergiram três plântulas, enquanto uma única semente germinou quatro embriões. Alguns trabalhos apontam a poliembrionia em $H$. serratifolius como resultado de apomixia esporofítica pseudogâmica com embriões adventícios decorrentes da hipóstase e tegumento do óvulo. A poliembrionia é um processo importante e estratégico para manutenção do ciclo de vida de várias espécies, com isso trabalhos que investiguem essa temática são importantes na construção de um maior entendimento do seu funcionamento.
\end{abstract}

The objective of this research was to record and evaluate the frequency and effects of polyembryony occurrence in Handroanthus serratifolius (Vahl) S. Grose, through a case study observed in seedling production for the reforestation project of degraded areas in Morro do Alecrim, Caxias-MA. To obtain the seeds, ripe and dried fruits of $\mathrm{H}$. serratifolius were collected and germination tests were carried out, showing the existence of several embryos in some seeds. From the 100 seeds submitted to the test, $70 \%$ of the seeds were germinated, 47 presented only one embryo and 16 developed polyembryony where 12 seeds germinated two seedlings, 3 seeds emerged three seedlings, while a single seed germinated four embryos. Some studies point to polyembryony in H. serratifolius as a result of pseudogamous sporophytic apomixis with adventitious embryos resulting from egg hypostasis and integument. Polyembryony is an important and strategic process for the maintenance of the life cycle of several species, so works that investigate this theme are important in building a greater understanding of its operation.

\section{INTRODUÇÃO}

O fenômeno conhecido como poliembrionia (ocorrência em mais de um embrião em uma semente), tem se mostrado bem interessante no meio científico desde que foi relatado pela primeira vez por Leeuwenhoek em Citrus sp, no ano de
1719 (TISSERAT et al., 1979). Considerando as angisopermas, cerca de $78 \%$ dos casos de poliembrionia, surgem do tecido materno (poliembrionia adventícia) e 19\% decorrem da clivagem do embrião fertilizado (poliembrionia por clivagem) (GANESHAIAH et al., 1991).

Esta característica pode proporcionar diversas vantagens

\section{Keywords}

Germination

Apomixis 
as plantas, como por exemplo, elevar o número de embriões produzidos com a mesma quantidade de recursos, e aumentar a probabilidade de estabelecimento de pelo menos uma plântula de uma única semente. Todavia, a competição entre plântulas aumenta, afetando seu desenvolvimento e sobrevivência (BLANCHARD et al., 2010; MENDES-RODRIGUES et al., 2012).

Apesar de várias vantagens, não se sabe como a poliembrionia pode equilibrar as problemáticas com a ocorrência de diversos embriões alocados na mesma semente. Anomalias morfológicas, competição de ninhadas dentro da competição de sementes e plântulas durante o estabelecimento podem afetar a rotatividade de embriões em mudas (HOTCHKISS et al., 2008; MU et al., 2010, SHAANKER; GANESHAIAH, 1997, MENDES-RODRIGUES et al., 2012).

Segundo Johri et al. (1992) múltiplos embriões podem ser formados por reprodução sexuada ou assexuada. No caso da reprodução sexuada, além do embrião zigótico, embriões podem se originar a partir de outras células do gametófito, como antípodas e sinérgides, ou por clivagem do zigoto ou suspensor (BATYGINA; VINOGRADOVA, 2007). Na reprodução assexuada, os embriões podem ser formados a partir de células do nucelo ou dos tegumentos, sem haver fecundação, o que caracteriza o processo de apomixia por embrionia adventícia (BATYGINA; VINOGRADOVA, 2007; MENDES RODRIGUES, 2010).

A poliembrionia segundo Carman (1997) já foi relatada em 115 famílias de angiospermas, sendo um evento de ocorrência comum, já descrita em ervas daninhas que habitam a região neotropical (ASKER; JERLING, 1992; NAUMOVA, 1992) e fortemente estudado em algumas famílias lenhosas da região tropical como Malvaceae (MENDES-RODRIGUES et al., 2005) Melastomataceae (GOLDENBERG; SHEPHERD, 1998; MENDES-RODRIGUES, 2010) e principalmente em Bignoniaceae (COSTA et al., 2004; BACKERS; IRGANG, 2004; SILVA et al., 2010; MARCOLIN et al., 2013).

A família Bignoniaceae Juss. é reconhecida por incluir árvores, arbustos, lianas e trepadeiras com folhas opostas e compostas, flores vistosas com corola tubular, gamossépala e gamopétala, androceu epipétalo formado por quatro estames didínamos e um estaminódio, gineceu sincárpico, com dois carpelos e múltiplos óvulos por lóculo, fruto cápsula (loculicida ou septícida), com sementes aladas e endosperma reduzido (LOHMANN, 2004; FISCHER et al., 2004; JUDD et al., 2009).

Para a família Bignoniaceae são reconhecidas 112 gêneros e 840 espécies (LOHMANN; ULLOA, 2018). Possui distribuição pantropical, onde $80 \%$ das espécies conhecidas são neotropicais (GENTRY, 1980). O Brasil abriga 33 gêneros e mais de 410 espécies, sendo 177 endêmicas, com distribuição em formações florestais úmidas, tais como Floresta Amazônica e Mata Atlântica, com grande expressividade em outros tipos de vegetações, como de Cerrado e Caatinga (FLORA DO BRASIL 2020, 2019).

$\mathrm{O}$ primeiro caso registrado de poliembrionia em Bignoniaceae foi o de Piazzano (1998), ao realizar estudos citogenéticos em Tabebuia chrysotricha (Mart. ex DC.) Standl. e, posteriormente, Salomão e Allem (2001) observaram o fenômeno em Tabebuia ochracea (Cham.) Standl., através de estudos de germinação de sementes. Dados histológicos coletados em algumas espécies de Bignoniaceae como Handroanthus ochraceus (Cham.) Mattos. (COSTA et al., 2004), H. chrysotrichus (Mart. ex DC.) Mattos. (BITTENCOURT JUNIOR; MORAES, 2010) e Anemopaegma acutifolium DC. (SAMPAIO et al., 2013) demonstraram que a poliembrionia surgem dos tecidos somáticos do óvulo, com isso sementes poliembrionárias têm sido usadas como evidência de apomixia esporofítica em Bignoniaceae (MENDESRODRIGUES et al., 2012; FIRETTI-LEGGIERI et al., 2013; SAMPAIO et al., 2013).

Diante da importância ecológica e econômica voltada a família Bignoniaceae, principalmente pelo uso na restauração de áreas degradadas e o crescente interesse de estudos de poliembrionia em espécies da família, o objetivo da pesquisa foi registrar e avaliar a frequência e efeitos da ocorrência de poliembrionia em Handroanthus serratifolius (Vahl) S. Grose, através de um estudo de caso sobre a produção de mudas para o projeto de reflorestamento de áreas degradadas no Morro do Alecrim, no Centro de Estudos Superiores de Caxias/CESC, da Universidade Estadual do Maranhão/UEMA, em Caxias/MA.

\section{MATERIAL E MÉTODOS}

Handroanthus serratifolius é uma árvore com 30-37m de altura; sua flor demonstra uma corola tubular infundibuliforme de coloração amarela; o fruto é uma cápsula linear, com muitos nectários extraflorais com a presença de várias sementes retangulares aladas, com germinação simples (GENTRY, 1992; ALVES et al., 2013). Para obtenção das sementes foram coletados frutos maduros e secos de $H$. serratifolius, na estação reprodutiva da espécie que compreende setembro a dezembro.

As sementes foram retiradas manualmente dos frutos para realização do ensaio germinativo, onde foram utilizadas 100 sementes, nos dias subsequentes às coletas de campo, submetidas à germinação no Laboratório de Biologia Vegetal/LABIVE, do CESC/UEMA, com temperaturas entre 20 e $25{ }^{\circ} \mathrm{C}$, com uso de placas de petri, com papel umedecido e água filtrada. No início da germinação das sementes, as 
mesmas foram transplantadas do papel umedecido para bandejas de germinação de papelão prensado, como sementeiras, possuindo 30 células cada, utilizando até três bandejas para continuação da germinação das sementes (Figura 1).

Foi utilizado como adubo fibras de coco nas células para desenvolvimento das sementes. Sementes sem embrião ou malformadas foram descartadas. O experimento de germinação foi acompanhado diariamente, para tanto, foi considerada germinada a semente que apresentou o rompimento dos tegumentos e a emergência da raiz principal. Todos os dados foram registrados, indicando o número de germinação, o número de sementes com poliembrionia, o número de embrião formados por sementes e o número de sementes mortas.

\section{RESULTADOS E DISCUSSÃO}

Foram necessários 12 dias, desde o início até o termino da germinação das sementes, com início em 09/10/2019 e finalizado em 21/10/2019. O início da germinação ocorreu no dia 15/10/2019, com 39\% de sementes germinadas na primeira análise. Posteriormente, no dia 21/10/2019, observou-se a germinação de $70 \%$ das sementes e $30 \%$ das sementes nunca foram germinadas (Figura 2). Do percentual que germinou, 7 sementes (10\%) não obtiveram sucesso, apesar da protrusão da radícula, não teve continuidade do processo germinativo.

Das 63 sementes que obtiveram sucesso na germinação por completo (com rompimento dos tegumentos e a emergência da raiz principal), 47 (75\%) apresentaram apenas um embrião e 16 (25\%) desenvolveram poliembrionia, onde 12 sementes (20\%) germinaram duas plântulas, 3 sementes (4\%) emergiram três plântulas, enquanto uma única semente (1\%) germinou quatro embriões (Figura 2). Foi verificado a tendência da distribuição dos dados observando que o número de embriões aumenta à medida que o número de sementes diminui, com coeficiente de determinação de 0,9973 , demonstrando que a variável dependente consegue ser explicada pelos regressores presentes no modelo.

$O$ que se sabe atualmente, é que a poliembrionia foi descrita para populações autocompatíveis e poliplóides de $H$. serratifolius, como resultado de apomixia esporofítica pseudogâmica, com embriões adventícios decorrentes da hipóstase e tegumento do óvulo (BITTENCOURT JÚNIOR; MORAES, 2010; BITTENCOURT JÚNIOR; SEMIR, 2005; COSTA et al., 2004; PIAZZANO, 1998; SAMPAIO, 2010), em que essa característica é comum na espécie e sugere que com esse advento a espécie possui vantagens adaptativas sobre outras espécies sexuais de Handroanthus (ASKER; JERLING, 1992; HÖRANDL, 2010; HÖRANDL; PAUN, 2007).

Em comparação com os dados de poliembrionia

Figura 1. Etapas do teste de germinação das sementes de H. serratifolius. A. Semente da espécie; B. Bandeja de germinação com substrato; C. Bandeja de germinação com as plântulas; D. Semente com dois embriões.

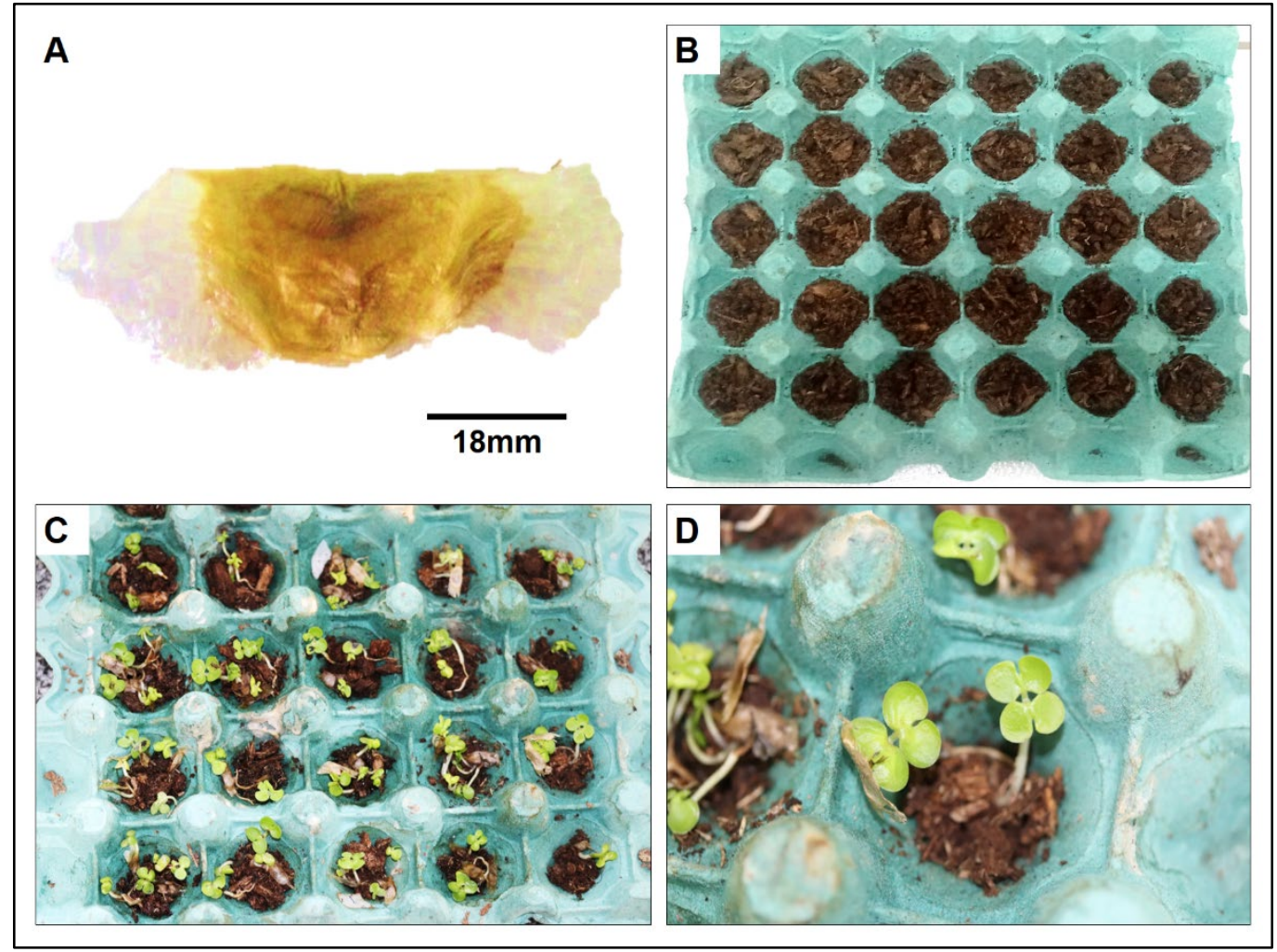

Fonte: Autores (2019). 
amostrados, Mendes-Rodrigues et al. (2012) analisando populações de $H$. serratifolius verificaram altas frequências de sementes poliembrionárias (21-91\%), observando que a medida que o número de embriões aumenta, também há um aumento das anomalias morfológicas embrionárias, mas com maior sobrevivência individual das sementes (Figura 3). Assim os autores concluíram que alta frequência de sementes poliembrionárias e o aumento da sobrevivência individual das sementes corroboram a hipótese que a poliembrionia representa um mecanismo reprodutivo alternativo que pode favorecer $H$. serratifolius.

$H$. serratifolius é uma espécie típica do Cerrado e a presença de processos sexuais de reprodução, via semente, sejam quase exclusivos em espécies do Cerrado (OLIVEIRA; GIBBS, 2000), a reprodução assexuada através da semente (apomixia), também vem sendo cada vez mais observada entre as espécies neste domínio (SALOMÃO; ALLEM, 2001). Por mais que se conheça a presença da poliembrionia dentre as espécies de Cerrado, os dados disponíveis, não descrevem os processos de desenvolvimento dos vários embriões (ARAÚJO, 2015).

Alguns autores afirmam que a ocorrência de processos apomíticos poderiam funcionar como uma forma de compensação reprodutiva no caso do embrião sexual se revelar inviável (PORCHER; LANDE, 2005). Dessa forma a ocorrência da poliembrionia permitiria à semente que, em decorrência de problemas com a formação do embrião sexuado, um dos embriões extranumerários pudesse ocupar o lugar do embrião sexuado, permitindo a formação de sementes com embriões viáveis (MENDES-RODRIGUES, 2010).

Figura 2. Gráfico de distribuição do número de sementes relacionado ao número de embriões de $H$. serratifolius com menção da linha de tendência exponencial e cálculo do coeficiente de determinação (R2).

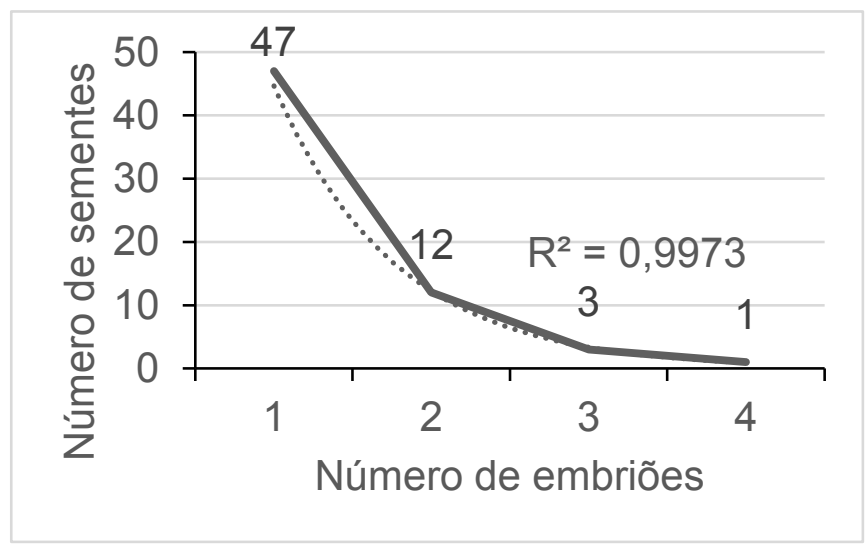

Figura 3. Exemplares de sementes de $H$. serratifolius, com apenas um embrião por semente (A), com dois embriões (B), com três embriões (C-D) e com quadro embriões (E).

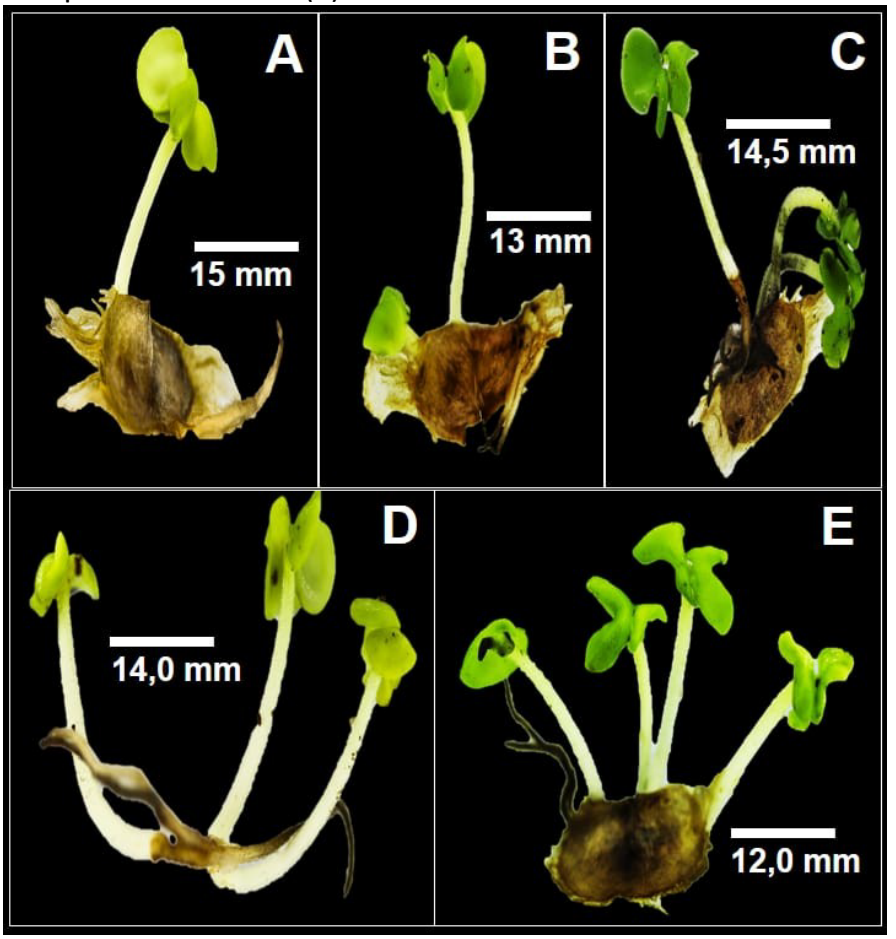

Fonte: Autores (2019). 


\section{CONSIDERAÇÕES FINAIS}

A poliembrionia é um processo importante e estratégico para manutenção do ciclo de vida de várias espécies vegetais, e que trabalhos que investiguem essa temática são importantes na construção de um maior entendimento do seu funcionamento. Dessa forma, o estudo realizado, contribuiu para novas observações de eventos de poliembrionia, o que amplia o entendimento do conhecimento para espécie $H$. serratifolius.

\section{AGRADECIMENTOS}

A Universidade Estadual do Maranhão/UEMA, pela concessão da bolsa iniciação cientifica; A AGA - Assessoria de Gestão Ambiental, pela oportunidade da participação no projeto de produção de mudas e reflorestamento - sementes que geram vidas; a mestranda Alice Torres, do PPGBAS/UEMA pela realização das imagens desta nota técnica; ao Professor Portela pela coleta dos frutos e sementes de ipê-amarelo, e ao Laboratório de Biologia Vegetal/LABIVE, pela infraestrutura disponibilizada para a pesquisa.

\section{REFERÊNCIAS}

ALVES, M. F.; DUARTE, M. O.; OLIVEIRA, P. E.; SAMPAIO, D. S. Self-sterility in the hexaploid Handroanthus serratifolius (Bignoniaceae) the national flower of Brazil. Acta Botânica Brasílica. v. 27, p. 714-722, 2013.

ARAÚJO, N. A. V. Embriologia, Apomixia e Poliembrionia em Inga laurina (Sw.) Willd (Fabaceae - Mimosoideae). Dissertação de mestrado. Universidade Federal de Uberlândia. p. 121, 2015.

ASKER, S. E.; JERLING, L. Apomixis in Plants. CRC Press, Boca Raton. p. 298, 1992.

BACKERS, P.; IRGANG, B. Árvores do Sul: guia de identificação e interesse ecológico. As principais espécies nativas sulbrasileira. São Paulo: UNISA, p. 325, 2004.

BATYGINA, T. B.; VINOGRADOVA, G. Y. U. Phenomenon of polyembryony. Genetic heterogeneity of seeds. Russian Journal of Developmental Biology. v. 3, n. 38, p. 126-151, 2007.

BITTENCOURT JÚNIOR, N. S.; MORAES, C. I. G. A autofertilidade e poliembrionia em ipês amarelos da América do Sul (Handroanthus chrysotrichus e H . Ochraceus, Bignoniaceae) um estudo histológico de eventos póspolinização. Plant Systematics and Evolution. v. 288, p. 5976, 2010.

BITTENCOURT JÚNIOR, N. S.; SEMIR, J. Autoincompatibilidade de ação tardia e outros sistemas de melhoramento em Tabebuia (Bignoniaceae). International Journal of Plant Sciences. v. 166, p. 493-506, 2005.

BLANCHARD, M. L.; BARNEY, J. N.; AVERILL, K. M.; MOHLER, C.

L.; DITOMMASO, A. Does polyembryony confer a competitive advantage to the invasive perennial vine Vincetoxicum rossicum (Apocynaceae)? American Journal of Botany. v. 97, p. 251-260, 2010.

CARMAN, J.G. Asynchronous expression of duplicate genes in angiosperms may cause apomixis, bispory, tetraspory, and polyembryony. Biological Journal of the Linnean Society. v. 61, p. 51-94, 1997.

COSTA, M. E.; SAMPAIO, D. S.; PAOLI, A. A. S.; LEITE, S. C. A. L. Poliembrionia e aspectos da embriogênese em Tabebuia ochracea (Chamisso) Standley (Bignoniaceae). Revista brasileira de Botânica. v. 27, n. 2, p. 395-406, 2004.

FIRETTI-LEGGIERI, F.; LOHMANN, L. G.; ALCÂNTARA, S.; COSTA, I. R.; SEMIR, J. Poliploidia e poliembrionia em Anemopaegma (Bignonieae, Bignoniaceae). Reprodução de Plantas. v. 26, p. 43-53, 2013.

FISCHER, E.; THEISEN, I.; LOHMANN, L. G. Bignoniaceae. In: KADEREIT, J. W. (ed.). The families and genera of vascular plants. Vol. VII. Springer-Verlag, Heidelberg. p. 9-38, 2004. FLORA DO BRASIL. FLORA DO BRASIL 2020 em construção. Jardim Botânico do Rio de Janeiro. 2019. Disponível em: < http://floradobrasil.jbrj.gov.br/ >. Acesso em: 04/11/2019.

GANESHAIAH, K. N.; UMA SHAANKER, R.; JOSHI, N. V. Evolution of polyembryony: Consequences to the fitness of mother and offspring. Journal of Genetics. v. 70, p. 103127, 1991.

GENTRY, A. H. Bignoniaceae Part I: Tribe Crescentieae and Tourrettieae. Flora Neotropica. v. 25, p. 1-117, 1980.

GENTRY, A.H. Bignoniaceae Part II: Tribe Tecomeae. Flora Neotropica. v. 25, p. 1-358, 1992.

GOLDENBERG, R.; SHEPHERD, G. J. Studies on the reproductive biology of Melastomataceae in "cerrado" vegetation. Plant Systematic Evolution. v. 211, p. 13-29, 1998.

HÖRANDL, E. The evolution of self-fertility in apomictic plants. Sexual Plant Reproduction. v. 23, p. 73-86, 2010.

HÖRANDL, E.; PAUN, O. Patterns and sources of genetic diversity in apomictic plants: implications for evolutionary potentials and ecology. In: HÖRANDL, E.; GROSSNIKLAUS, U.; VAN DIJK, P.; SHARBEL, T. F. Apomixis: Evolution, Mechanisms and Perspectives. ARG-Gantner, Rugell, p. 169-194. 2007.

HOTCHKISS, E. E.; DITOMMASO, A.; BRAINARD, D. C.; MOHLER, C. L. Survival and performance of the invasive vine Vincetoxicum rossicum (Apocynaceae) from seeds of different embryo number under two light environments. American Journal of Botany. v. 95, p. 447-453, 2008. 
JOHRI, B. M.; AMBEGAOKAR, K. B.; SRIVASTAVA, P. S. Comparative Embryology of Angiosperms. v. 1. SpringerVerlag Berlin Heidelberg p. 1221, 1992.

JUDD, W. S.; CAMPBELL, C. S.; KELLOGG, E. A.; STEVENS, P. F.; DONOGHUE, M. J. Sistemática vegetal: um enfoque filogenético. 3ạ ed. Artmed, Porto Alegre. p. 612, 2009.

LOHMANN, L. G. Bignoniaceae. In: SMITH, N.; MORI, S. A.; HENDERSON, A.; STEVENSON, D. W. M.; HEALD, S. Flowering Plants of the Neotropics. Princeton University Press, Princeton. p. 51-53, 2004.

LOHMANN, L. G.; ULLOA, C. U. Bignoniaceae. In: MOBOT/NYBG/Kew Gardens. Checklist of the World. 2018. Disponível em <http://www.iplants.org/>. Acesso em 10/02/2018.

MARCOLIN, G.; NAGAOKA, R. E.; PERES, F. S. B. Germinação e Poliembrionia em Sementes de Ipê-Dourado armazenadas. Enciclopédia Biosfera. v. 9, n. 17, p. 15391547, 2013.

MENDES-RODRIGUES, C. Ecologia de espécies poliembriônicas com ênfase no Bioma Cerrado. Tese de Doutorado. Universidade Federal de Uberlandia, Uberlândia MG. p. 248, 2010.

MENDES-RODRIGUES, C.; CARMO-OLIVEIRA, R.; TALAVERA, S.; ARISTA, M.; ORTIZ, P. L.; OLIVEIRA P. E. Polyembryony and apomixis in Eriotheca pubescens (Malvaceae Bombacoideae). Plant Biology. v. 7, p. 433-450, 2005.

MENDES-RODRIGUES, C.; SAMPAIO, D. S.; COSTA, M. G.; CAETANO, A. P. S.; RANAL, M. A.; BITTENCOURT JÚNIOR, N. S.; OLIVEIRA, P. E. Polyembryony increases embryo and seedling mortality but also enhances seed individual survival in Handroanthus species (Bignoniaceae). Flora. v. 207, p. 264-274, 2012.

MU, X.; JIN, B.; TENG, N. Studies on the early development of zygotic and synergid embryo and endosperm in polyembryonic rice ApIII. Flora. v. 205, p. 404-410, 2010.

NAUMOVA, T. N. Apomixis in Angiosperms: Nucellar and Integumentary Embryony. CRC Press. p. 152, 1992.

OLIVEIRA, P.E.; GIBBS, P.E. Reproductive biology of woody plants in a cerrado community of Central Brazil. Flora. v. 195, p. 311-329, 2000.

PIAZZANO, M. Números cromosómicos en Bignoniaceae de Argentina. Kurtziana. v. 26, p. 179-189, 1998.

PORCHER, E.; LANDE, R. Reprodutive compesation in the evolution of plant mating systems. New Phytologist. v. 166, p. 673-684, 2005.

SALOMÃO, A. N.; ALLEM, A. C. Polyembryony in angiospermous trees of the brazilian cerrado and caatinga vegetation. Acta Botanica Brasilica. v. 15, p. 369-378, 2001.

SAMPAIO, D. S. Biologia reprodutiva de espécies de Bignoniaceae ocorrentes no Cerrado e alterações no sistema de autoincompatibilidade. Tese de Doutorado,
Instituto de Biologia, Universidade Federal de Uberlândia, MG, Brasil. p. 232, 2010.

SAMPAIO, D. S.; BITTENCOURT JÚNIOR, N. S.; OLIVEIRA, P. E. Mating in the pseudogamic apomictic Anemopaegma acutifolium DC: Another case of pseudo-self-compatibility in Bignoniaceae? Plant Biology. v. 15, n. 5, p. 919-924, 2013.

SHAANKER, R.; GANESHAIAH. K. N. Conflict between parent and offspring in plants: predictions, processes and evolutionary consequences. Current Science. v. 72, p. 932939, 1997.

SILVA, D. G.; CARVALHO, M. L. M.; NERY, M. C.; OLIVEIRA, L. M.; CALDEIRA, C. M. Alterações fisiológicas e bioquímicas durante o armazenamento de sementes de Tabebuia serratifolia. Revista Cerne. v. 17, n. 1, p. 1-7, 2010.

TISSERAT, B.; ESAN, E. B.; MURASHIGE, T. Somatic embryogenesis in angiosperms. Horticultural Reviews. v. 1, p. 1-78, 1979.

Submissão: 09/11/2019

Aprovado para publicação: 16/11/2019 